\title{
Sarcopenia, more that dehydration, may be associate to underweight Portuguese centenarians
}

Alda Pereira da Silva (M.D., MSc.) ${ }^{1,2,3,4,5}$, Andreia Matos (BSc.) ${ }^{2,5}$, Ana Valente (Ph.D) ${ }^{6}$, Ângela Gil (BSc.) ${ }^{2,5}$, Isanete Alonso (BSc., MSc.) 2, 5, 7 , Ricardo Ribeiro (M.D., Ph.D.) ${ }^{2,5,8}$, Gorjão Clara (M.D.,Ph.D.) ${ }^{3,4}$ Manuel Bicho (M.D., Ph.D.) ${ }^{2,5}$

${ }^{1}$ Alameda Primary Care Health Center, Lisbon, Portugal; ${ }^{2}$ Genetics Laboratory and Institute of Environmental Health - ISAMB, University of Lisbon, Faculty of Medicine, Portugal; ${ }^{3}$ Universitary Geriatric Unit of Faculty of Medicine of Lisbon, University of Lisbon, Portugal ${ }^{4}$ Academic Medical Center of Lisbon - North of Lisbon Hospital Center; ${ }^{5}$ Institute of Rocha Cabral, Lisbon, Portugal; ${ }^{6}$ Atlantica University Nutrition Sciences Department and Institute of Environmental Health - ISAMB, University of Lisbon, Faculty of Medicine, Portugal; ${ }^{7}$ Nutrition division St Louis Hospital, Lisbon, Portugal; ${ }^{8}$ Molecular Oncology Group, Portuguese Institute of Oncology, Porto Centre OPorto, Portugal,

\section{OBJECTIVES}

1989, I Rosenberg defines sarcopenia as a decreases in muscle mass, one of the consequences of aging (1). 2010, appears a European Working Group on Sarcopenia in Older People (EWGSOP) (2):

Progressive and generalized loss of skeletal muscle mass and strength, or physical performance (gait speed), with a risk of adverse outcomes such as physical disability, poor quality of life and death. Prevalence range from $4.4 \%-94 \%$ across definitions (3). Fat-free mass has a functional significance in aging The objective of this study was to evaluate the prevalence of underweight in a Portuguese population of centenarians and their relationship with dehydration or sarcopenia.

\section{METHODS}

Anthropometric data were obtained using standard procedures from 252 centenarians (100.26 \pm 1.99 years), $77.8 \%$ women $(\mathrm{W})$

Body composition was assessed by tetrapolar bioimpedance (Tanita ${ }^{\circledR}$ BC-420MA) It was considered dehydration: total body water (TBW) $(\%)<45$ (W) and $<50$ Male $(\mathrm{M})$, and excess of fat mass (FM) (\%): $>35(\mathrm{~W})$ and $>25(\mathrm{M})$.

The fat mass index (FMlndex): FM $(\mathrm{kg}) /$ height $\left(\mathrm{m}^{2}\right)$ and muscle mass index (MMIndex): MM $(\mathrm{kg}) /$ height $\left(\mathrm{m}^{2}\right)$ were calculated.

Statistical methods: T-Student, ANOVA, Chi-square, linear correlation

Table1. Frequency of total body water and body fat mass and BMI subgroup body fat mass and BM
distribution in women and men.

\begin{tabular}{|c|c|c|c|c|}
\hline & $\begin{array}{l}\text { Overall } \\
N(\%(\%)\end{array}$ & $\begin{array}{l}\text { Women } \\
N(\%(\%)\end{array}$ & $\begin{array}{l}\text { Nen } \\
\mathrm{N}(\%)\end{array}$ & 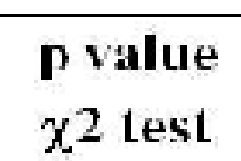 \\
\hline $\mathrm{TBW}<45 \%$ ( ) or $<50 \%($ & $21(12.9)$ & $19(15,4)$ & $2(5.0)$ & 0.087 \\
\hline Body fat mass $>35 \%($ ) or $>25(0)$ & $10(6.0)$ & $6(4.8)$ & $4(10.0)$ & 0.225 \\
\hline Underweight $(\mathrm{BMI}<\mathbf{1 8 . 5})$ & $61(25.3)$ & $54(28.8)$ & $7(13.2)$ & \\
\hline Normal weight (BMM $* 1.5$ and $<25$ ) & $148(61.4)$ & $114(60.6)$ & $34(64.2)$ & 0.014 \\
\hline Overweight it & $32(13.3)$ & $20(10.6)$ & $12(22.6)$ & \\
\hline
\end{tabular}

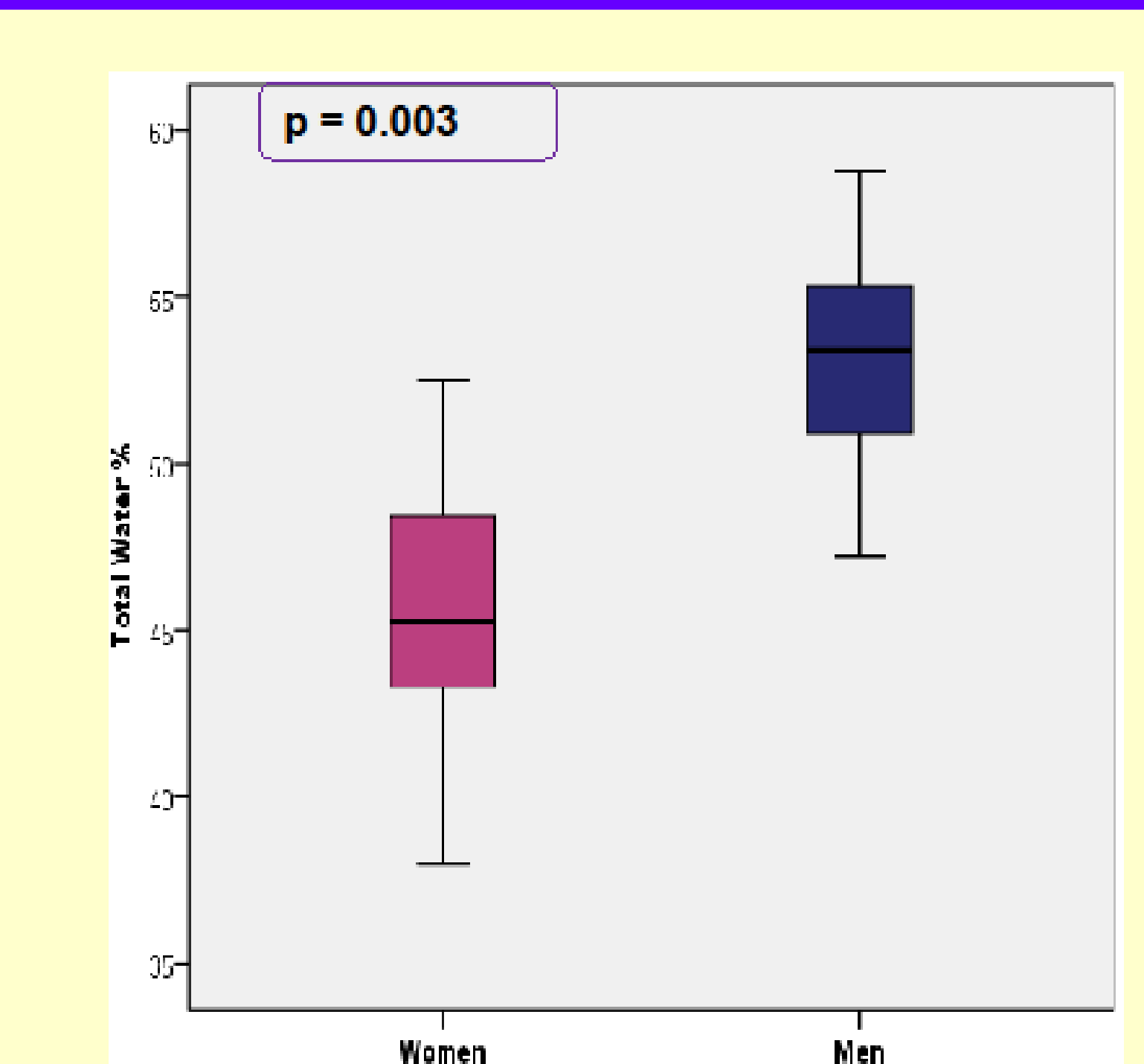

Fig 1. Level of hydratation in women and men of global sample

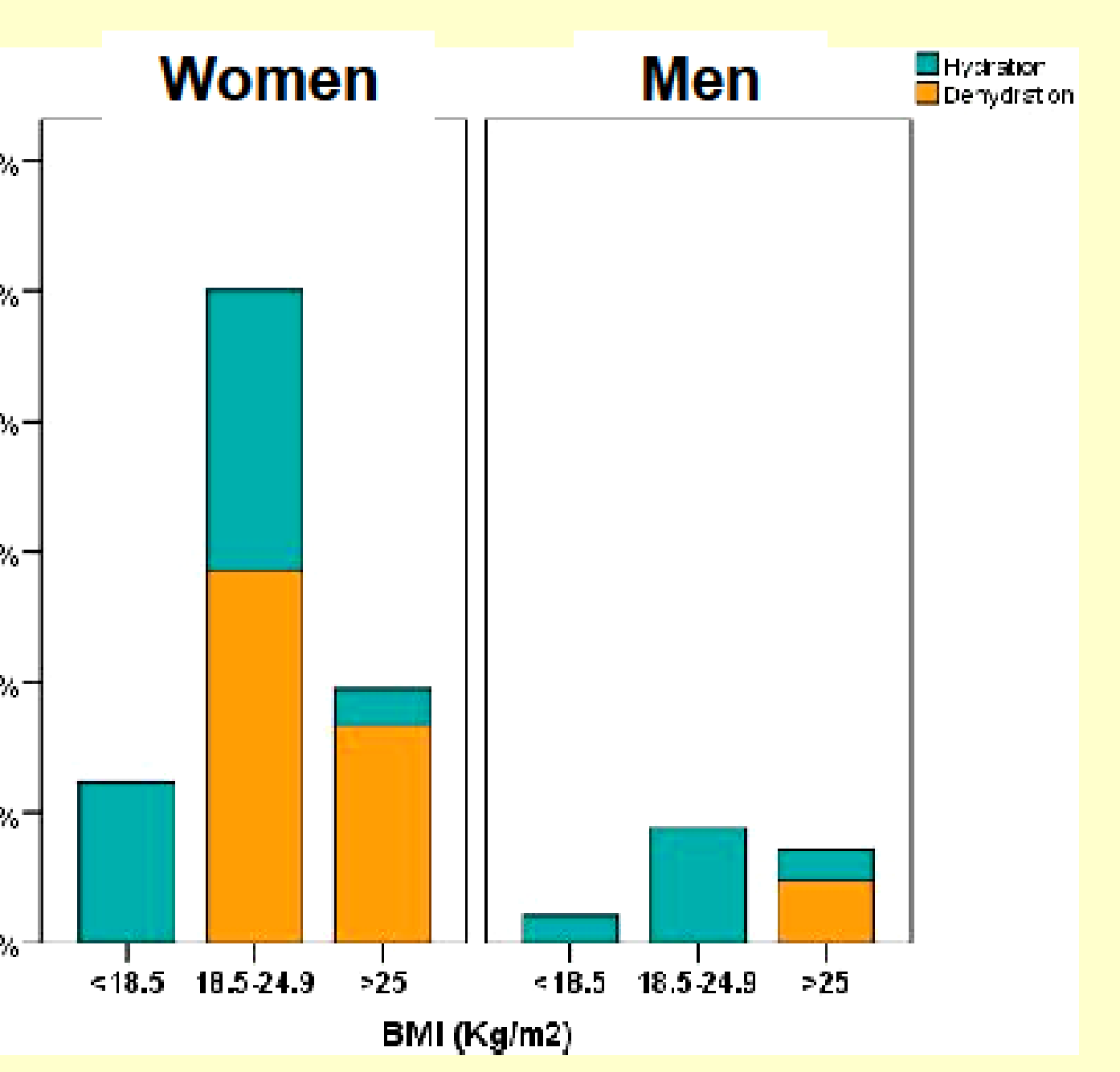

Fig 2. Frequency of dehydration in women and men according to BMI

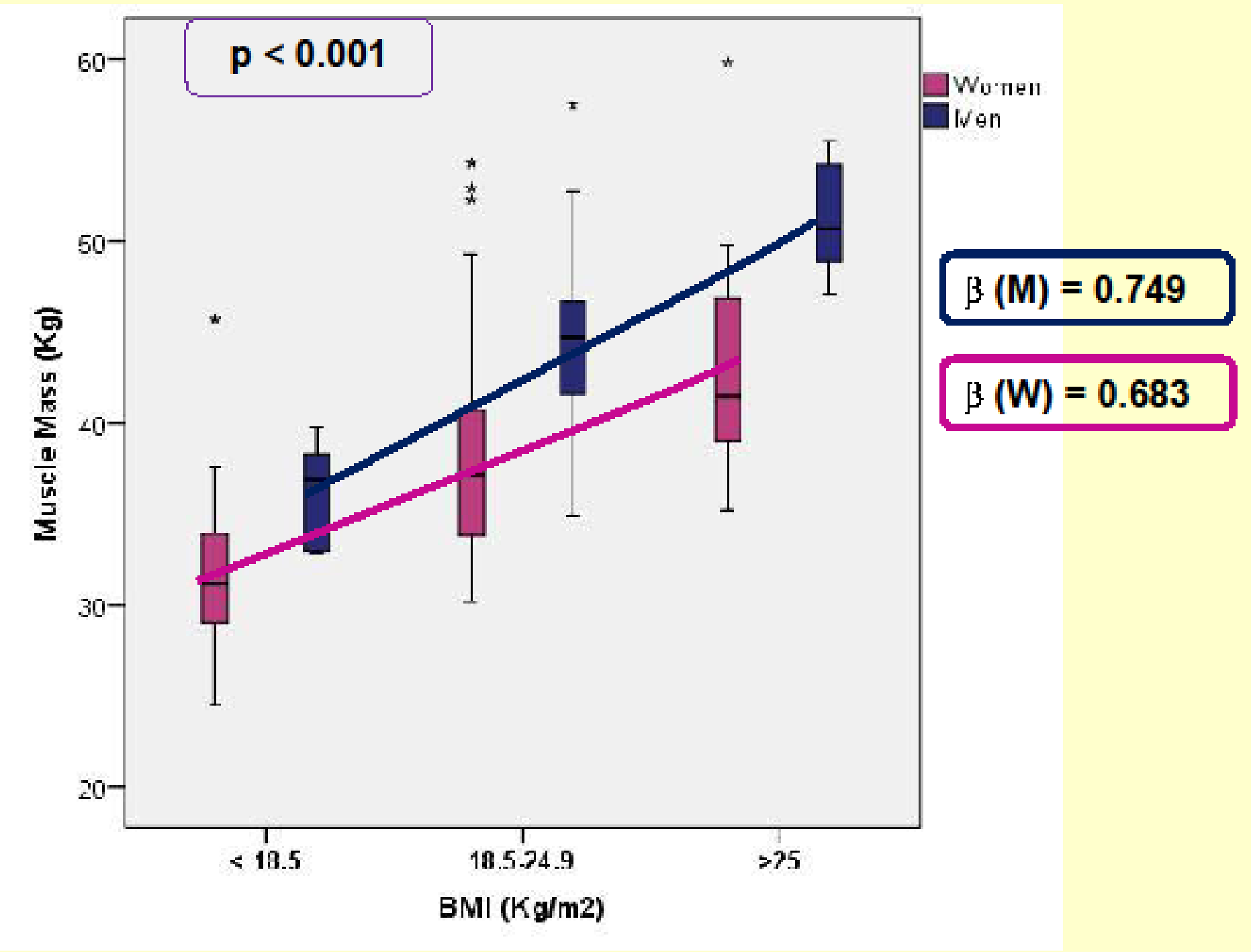

Fig 3. Muscle mass and BMl subgroup in women and men of global sample

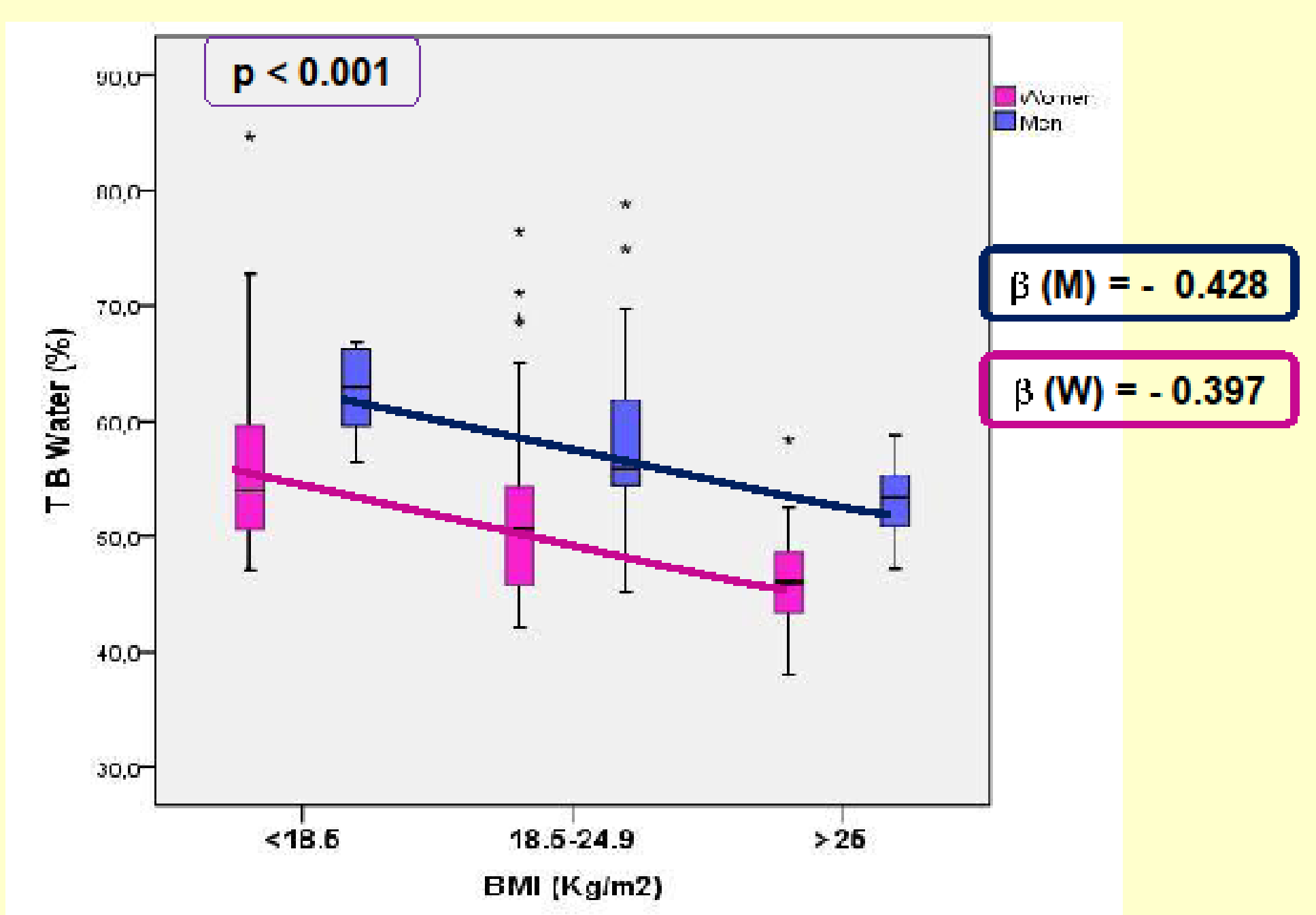

Fig 4. Total body water and BMI subgroup in women and men of global sample

\section{RESULTS}

In the sample, $61.4 \%$ had normal weight $(\mathrm{BMI}=21.42 \pm 1.86)$, but $25.3 \%$ were underweight $(\mathrm{BMI}=16.84 \pm 1.51)$, and of these, $28.8 \%$ were women Instead, overweight $(\mathrm{BMI}=27.52 \pm 2.40)$ checked in $13.3 \%$ subjects, was predominant in men (10.6 vs. 22.6\%) (Table 1). Men showed hydration levels superior to women (Fig. 1). Dehydration was observed in $12.9 \%$ of subjects and was tendentiously higher in women (15.4 vs. $5.0 \%, p=0.087$ ). Excess of FM was found in $6.0 \%$ of subjects with no gender differences $(p=0.225)$ (Table 1$)$. In the overweight subgroup there were differences in TBW $(p=0.003)$ and FM ( $p=0.022)$ between genders, which was not observed in the underweight subgroup (Fig. 2). The FMlndex in underweight or overweight subgroups did not vary significantly with gender. Muscle mass and MMIndex were different between genders, with the lowest values observed in underweight $\mathrm{W}$ compared to $\mathrm{M}(31.7 \pm 3.96$ vs. $36.3 \pm 2.84 ; \mathrm{p}=0.01)$ or to the other subgroups. There was a direct linear correlation between $\mathrm{BMI}$ and $\mathrm{MM}(\beta(\mathrm{M})=0.749 ; \beta(\mathrm{W})=0.683)$ and inverse with TBW $(\beta(\mathrm{M})=-0.428 ; \beta(\mathrm{W})=-0.397)$, men and women, $\mathrm{p}<0.001(\mathrm{Fig} 3$ and 4$)$.

\section{DISCUSSION}

Studies report that centenarians are usually thin (4). Height and weight of Portuguese centenarians are similar to reported anthropometric characteristics in Italian centenarians $(5,6)$. Looking at the results can be seen that the leaner individuals showed higher degree of hydration, but smaller muscle mass in relation to the other subgroups. The cut-off points, essential to define low muscle mass are in discussion

In Polish elderly individuals, are $5.52 \mathrm{~kg} / \mathrm{m} 2$ for females and $7.29 \mathrm{~kg} / \mathrm{m} 2$ for men (7), close to established by Beaudart 2014 for Caucasian Americans (8) and EWGSOP consensus (7.25-7.26 kg/m² for men and $5.5-5.67 \mathrm{~kg} / \mathrm{m}^{2}$ for women) (9).

\section{CONCLUSIONS}

The underweight was more represented in the Portuguese centenarians. More than body water and FM, sarcopenia may be responsible for this low weight particularly in the women.

\section{References}

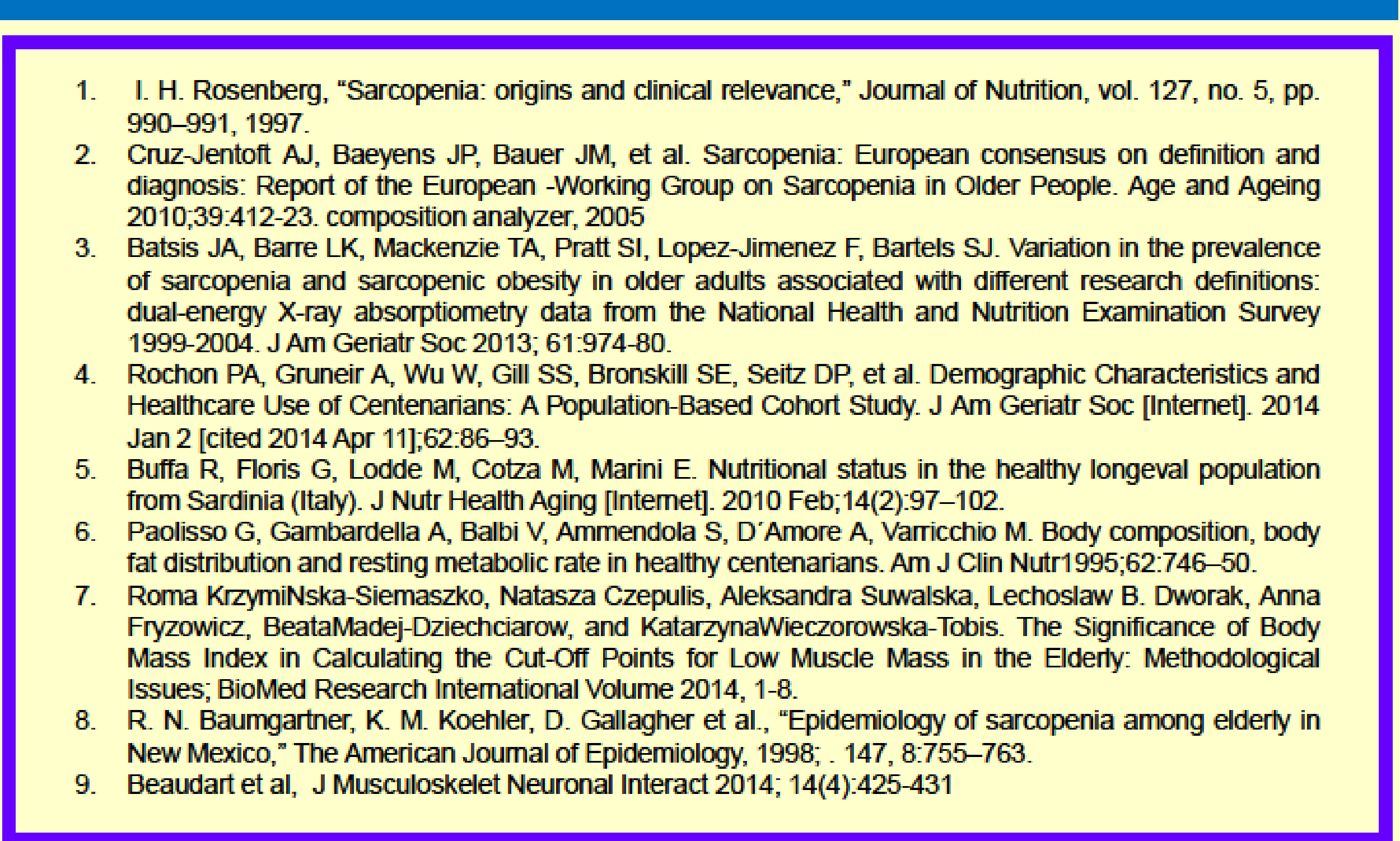

17th European Congress of Endocrinology, 16 - 20 May 2015, Dublin, Ireland ROCHACABRAL 